\title{
Effects of and barriers to hospital-based pulmonary rehabilitation in patients with chronic obstructive pulmonary disease
}

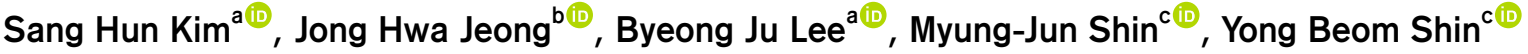 \\ ${ }^{a}$ Department of Rehabilitation Medicine, Biomedical Research Institute, Pusan National University Hospital, Busan, Republic of Korea \\ ${ }^{b}$ Department of Physical Therapy, Rehabilitation Medicine, Pusan National University Hospital, Busan, Republic of Korea \\ 'Department of Rehabilitation Medicine, Biomedical Research Institute, Pusan National University Hospital, Pusan National University School \\ of Medicine, Busan, Republic of Korea
}

Objective: The purpose of this study was to assess the effect of hospital-based pulmonary rehabilitation (PR) on exercise capacity and quality of life as well as barriers to participation in persons with chronic obstructive pulmonary disease (COPD) in South Korea.

Design: One-group pretest-posttest design.

Methods: A total of 14 patients were enrolled in this study in an 8-week PR program with two 60-minute sessions per week. The program included: flexibility exercises, breathing techniques, strengthening exercises, and aerobic exercises. The outcomes were defined as changes in the variables before and after the PR program. A change in the 6-minute walk distance (6MWD) was defined as the primary outcome, and changes in pulmonary function test, respiratory and grip strength, and the St. George's Respiratory Questionnaire (SGRQ) about quality-of-life results were secondary outcomes. A dropout was defined as missing $>3$ of the 16 sessions.

Results: Patients who completed the program showed a significant improvement of $43.57 \pm 39.43 \mathrm{~m}$ in the $6 \mathrm{MWD}$ ( $p<0.05$ ), but no significant differences were noted for the other function tests. The SGRQ showed a significant improvement in the activity and total score $(p<0.05)$. The total dropout rate was 53.3\%. Newly developed symptoms, exacerbation of COPD, transport problems, and lack of motivation were major barriers to PR.

Conclusions: Our study showed that an 8-week hospital-based PR program improved exercise capacity and quality of life but had a high dropout rate in individuals with COPD. Since comprehensive PR has only recently been established in South Korea, patient motivation and education are critical.

Key Words: Exercise, Lung Diseases, Obstructive, Quality of life, Rehabilitation

\section{Introduction}

Pulmonary rehabilitation (PR) as a multidisciplinary integrated program is tailored to the individual situation based on multiple assessments. It aims to improve the physical and emotional state of persons with chronic lung disease [1]. To this end, PR programs should include not only exercises to improve physical performance, but also psychiatric assessments to recognize social isolation, anxiety, and depression, as well as interventions such as nutritional therapy and comprehensive education [2]. These problems are complex and closely related to each other. If only one of them improves, this may break the vicious cycle and positively affect the overall situation of a patient.

Received: 17 April, 2020 Revised: 28 April, 2020 Accepted: 4 May, 2020

Corresponding author: Yong Beom Shin (ORCID https://orcid.org/0000-0001-5026-1696)

Department of Rehabilitation Medicine, Pusan National University Hospital, Pusan National University School of Medicine, 179 Gudeok-ro, Seo-gu, Busan 49241, Republic of Korea

Tel: 82-51-240-7485 Fax: 82-51-247-7485 E-mail: yi0314@gmail.com

(c) This is an Open-Access article distributed under the terms of the Creative Commons Attribution Non-Commercial License (http://creativecommons.org/licenses/ by-nc/4.0) which permits unrestricted non-commercial use, distribution, and reproduction in any medium, provided the original work is properly cited.

Copyright () 2020 Korean Academy of Physical Therapy Rehabilitation Science 
According to the Korean National Health and Nutrition Examination Survey in 2008, 13.4\% of the population aged 40 years and older were diagnosed with chronic obstructive pulmonary disease (COPD) [3]. COPD is an important disease from a public health perspective not only because it is frequent but also because it can be prevented and treated. PR has proven benefits in persons with COPD as a non-pharmacological treatment based on high-quality evidence [4]. Forced expiratory volume in one second $\left(\mathrm{FEV}_{1}\right)$, which can be measured in pulmonary function tests, is important for the evaluation of COPD patients but not sufficient as a selection criterion for PR. Respiratory distress, which is not necessarily correlated with the results of pulmonary function testing, reduces patients' ability to exercise and affects their activities of daily life. Therefore, PR should be considered for COPD patients whose symptoms persist despite appropriate medical treatment or those who have confirmed exercise intolerance or poor quality of life [5].

While many studies have proven the benefits of PR, a 2013 survey of respiratory physicians with more than 500 hospital beds in Korea reported that more than $70 \%$ of centers did not provide PR [6]. In fact, even hospitals that provide PR reported that they were unable to perform the comprehensive rehabilitation that is recommended in guidelines. The main reason was the lack of reimbursement within the Korean National Health Insurance, which results in poor rehabilitation facilities.

With the introduction of reimbursement for PR in December 2016, however, it became possible to establish proper rehabilitation facilities in hospitals that can provide comprehensive PR to South Korean patients. Since the opening of its PR center in 2016, our hospital has gradually implemented a comprehensive PR program. The purpose of this study was to investigate the effect of an 8-week hospitalbased PR program with two sessions per week on the exercise capacity and quality of life in individuals with COPD and to identify potential barriers to PR.

\section{Methods}

\section{Participants}

The study was a prospective single-arm intervention study at a single center. Based on a previously published study with the change in the 6-minute walk distance (6MWD) as the primary outcome, a sample size of 22 subjects was calculated to be necessary for $80 \%$ power and a type 1 error of $5 \%$ [7]. Dropouts were defined as subjects who did not partic- ipate in more than 3 of the 16 sessions. Assuming a dropout rate of about $30 \%, 30$ subjects were considered necessary. Among 556 patients who were treated for COPD at our hospital between August 2017 and August 2018, 59 patients were referred to the Department of Rehabilitation Medicine for this study. After applying the following inclusion criteria: 1) $>40$ years, 2) symptoms such as dyspnea or exercise intolerance in their daily lives, 3) Non-smoker or patient who has quit smoking for 3 months, 4) post-bronchodilator $\mathrm{FEV}_{1} /$ forced vital capacity $(\mathrm{FVC})<0.7$ in pulmonary function test, and 5) adequate pharmacological treatment following the Global Initiative for Chronic Obstructive Lung Disease COPD strategy [4], 30 patients were included. Based on the exclusion criteria: 1) difficulty walking or any disease preventing improvement in walking ability, 2) uncontrolled extrapulmonary disease that could lead to hemodynamic instability during exercise (for example, angina pectoris, arrhythmia, or uncontrolled diabetes mellitus), 3) participation in other clinical studies, 4) resting hypoxemia due to severe respiratory failure $\left(\mathrm{SpO}_{2}<90 \%\right)$, we excluded 29 patients. Consequently, we enrolled 30 patients in the study. Subjects who met the criteria were screened, and informed consent was obtained after a detailed description of the study procedures. Medications to improve symptoms during the study were managed by pulmonologists. The intervention was scheduled to last for 8 weeks. Ethics approval was obtained from the Institutional Review Board (IRB) of Pusan National University Hospital (IRB No. 1706-003-056). All procedures of the study were performed in accordance with the amended Declaration of Helsinki. Approval included the protocol and consent form used to obtain written informed consent from all subjects. All participants provided written informed consent. In addition, this study was registered at Clinical Research Information Service (approval No. KCT0004563).

\section{Pulmonary rehabilitation program}

An experienced physiotherapist conducted a one-hour comprehensive PR program twice a week for a total of 8 weeks. The program consisted of the following components: 1) flexibility exercises; 2) breathing techniques; 3 ) strengthening exercises; and 4) aerobic exercises (Figure 1).

Flexibility exercises or chest-mobilizing exercises involved stretching the trunk and limbs while breathing deeply [8]. During inspiration, the rib cage expands and the ribs move up. During exhalation, the rib cage contracts, and the ribs descend towards the pelvis, while the arms are used to increase the mobility of the rib cage. The following three movements 

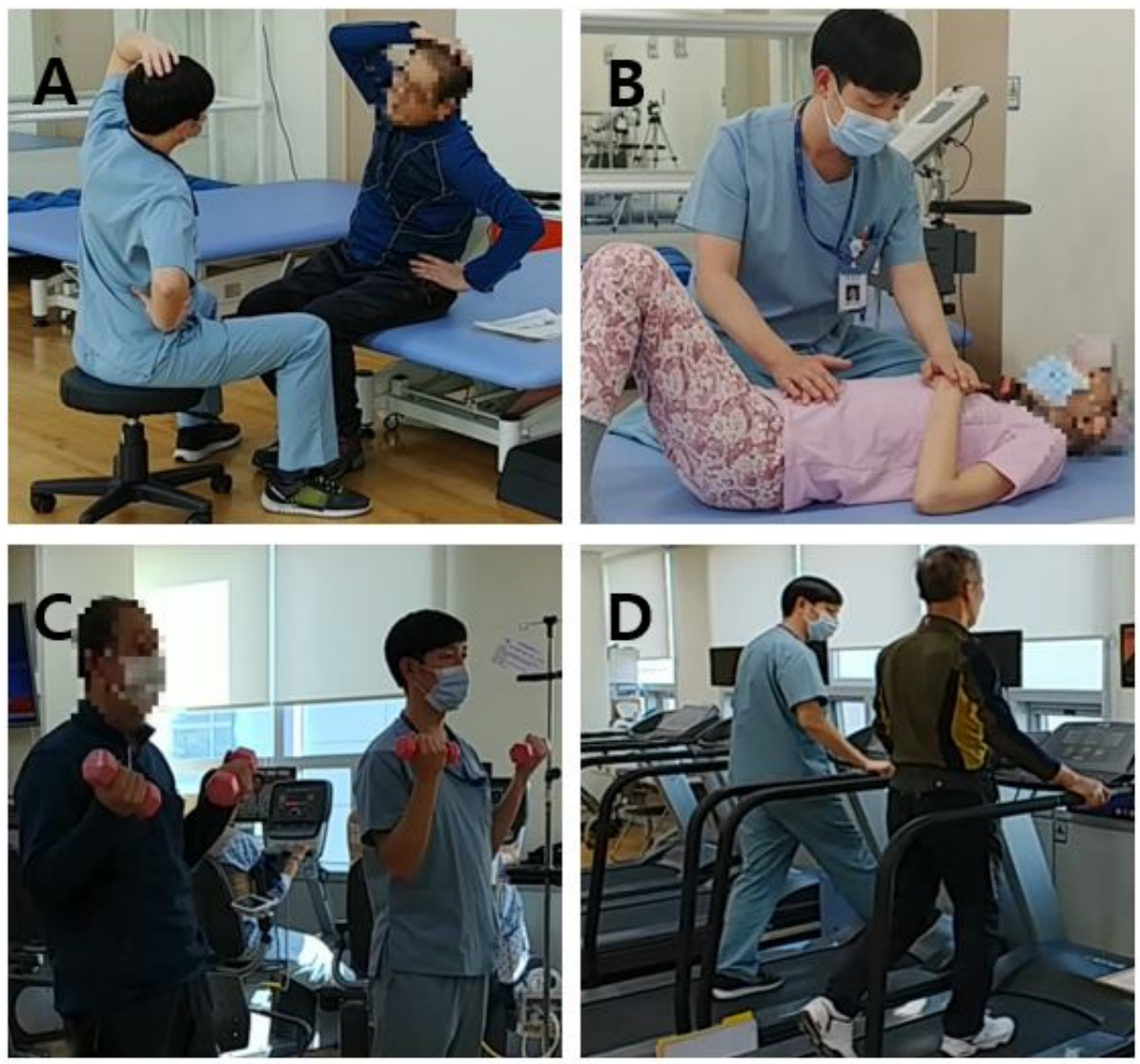

Figure 1. The program of pulmonary rehabilitation. (A) Flexibility exercise. (B) Breathing technique. (C) Strengthening exercise. (D) Aerobic exercise.

were repeated five times each: pectoralis stretching, shoulder stretching, and lateral trunk stretching.

Breathing techniques included diaphragmatic and pursedlip breathing during the first three visits and were repeated for 5-10 minutes under supervision. The therapist also monitored the use of these breathing techniques during exercise. During pursed-lip breathing, the patient breathes air slowly and deeply into the nose with a relaxed neck and shoulders. During exhalation, patients purse their lips and release the air slowly. The ratio of inspiration to exhalation is $1: 2$, and patients should avoid forced exhalation and instead breathe out slowly [9]. During diaphragmatic breathing, patients put their hands on the chest and abdomen and are instructed to breathe and focus on feeling their abdomen moving rather than their chest.

The strengthening and aerobic exercises applied the 'Frequency, Intensity, Time and Type' principle recommended by the American Thoracic Society [10]. For strengthening exercises, an intensity of $60 \%$ of the one-repetition maximum is recommended. However, in older patients, the onerepetition maximum often cannot be measured because of musculoskeletal problems. Therefore, exercise intensity was determined based on the four-to-six-repetitions maximum in a submaximal strength test [11]. The training was composed of three sets of 10 repetitions each. Elbow flexion was performed to train the arms. Sitting knee extensions were recommended to train the legs and strengthen the quadriceps muscle, which often becomes dysfunctional in COPD [12].

Aerobic exercises are recommended three to five times per week by the American College of Sports Medicine and American Association of Cardiovascular and PR [5,13]. In this study, they were conducted for 30 minutes per session, twice a week. The intensity of the exercise was prescribed based on $60 \%$ of the speed for the 6MWD in each patient's individual 6-minute walk test (6MWT) and was gradually increased up to $80 \%$ of the maximum speed. However, since the 6MWT is a submaximal test, the speed was gradually increased when patients did not reach a score of 5 on the Borg Category/Ratio-10 Scale. Table 1 shows the specific exercise prescription for the PR program of this study.

\section{Outcome assessments}

The outcomes were defined as changes in the variables before and after the 8 weeks of the PR. Outcome assess- 
Table 1. The program of pulmonary rehabilitation of this study

\begin{tabular}{|c|c|c|}
\hline Types of exercise & Session 1-3 & Session 4-16 \\
\hline Flexibility exercises & \multicolumn{2}{|c|}{$\begin{array}{l}\text { Repeated five times with controlled breathing } \\
\text { a. Pectoralis stretching } \\
\text { b. Shoulder stretching } \\
\text { c. Trunk lateral stretching }\end{array}$} \\
\hline Breathing techniques & $\begin{array}{l}\text { Diaphragmatic breathing and pursed lip breathing } \\
\text { repeated for 5-10 min under supervision }\end{array}$ & Applying breathing techniques during the exercise \\
\hline Strengthening exercises & $\begin{array}{l}\text { a. Frequency: } 2 \text { times } / \text { wk } \\
\text { b. Intensity: } 60 \% \text { of calculated } 1 \mathrm{RM} \\
\text { c. Time: } 10 \text { times } \times 3 \text { sets } \\
\text { d. Type: dumbbell, leg extension machine }\end{array}$ & $\begin{array}{l}\text { a. Frequency: } 2 \text { times } / \text { wk } \\
\text { b. Intensity*: } 60 \% \text { of calculated } 1 \mathrm{RM} \\
\text { c. Time: } 10 \text { times } \times 3 \text { sets } \\
\text { d. Type: dumbbell, leg extension machine }\end{array}$ \\
\hline Aerobic exercises & $\begin{array}{l}\text { a. Frequency: } 2 \text { times } / \mathrm{wk} \\
\text { b. Intensity: } 60 \% \text { speed of } 6 \mathrm{MWT} \\
\text { c. Time: } 30 \mathrm{~min} \\
\text { d. Type: treadmill }\end{array}$ & $\begin{array}{l}\text { a. Frequency: } 2 \text { times } / \mathrm{wk} \\
\text { b. Intensity: } 80 \% \text { speed of } 6 \mathrm{MWT} \\
\text { c. Time: } 30 \mathrm{~min} \\
\text { d. Type: treadmill }\end{array}$ \\
\hline
\end{tabular}

1RM: one-repetition maximum, 6MWT: 6-minute walk test.

*Recheck 1 RM at 4 th visit. 1RM is the maximum amount of weight that a person can possibly lift for one repetition.

ments were conducted by another well-trained physiotherapist who was blinded to all patient information. The $6 \mathrm{MWD}$ was defined as the primary outcome, and the results of pulmonary function tests, respiratory and grip strength tests, and quality-of-life questionnaires were evaluated as secondary outcomes.

Exercise capacity was measured using the 6MWT according to the American Thoracic Society's Pulmonary Function Standard Committee guideline [14]. The 6MWT was performed on a 30-meter straight track under the supervision of a qualified physiotherapist, and the oxygen saturation and pulse rate were monitored in real-time using the wrist oximeter WristOx2 Model 3150 (Nonin Medical Inc., Minnesota, MN, USA). Dyspnea and leg fatigue were checked with the Borg Category/Ratio-10 Scale before and after exercise. Pulmonary function tests and maximal inspiratory pressure (MIP) and maximal expiratory pressure (MEP) were assessed in a standardized way using a desktop spirometer Pony FX (Cosmed, Rome, Italy) [15]. FVC was measured as the maximum inspiration and exhalation after three normal breaths.

MIP and MEP were the tests used to assess the strength of the respiratory muscles in our patients. The pressure values at maximum inspiration and exhalation were measured, and the maximum of three trials was recorded. The peak cough flow was measured with the MicroPeak peak flow meter (Carefusion GmbH, Höchberg, Germany) and recorded as the maximum value of three trials with short and forceful exhalation after maximum inspiration.
Grip strength was measured with a Jamar hydraulic hand dynamometer (Performance Health, Warrenville, IL, USA), starting with the right hand. The subject was seated in a neutral position, and grip strength was evaluated in shoulder adduction, $90^{\circ}$ flexion of the elbow, and with the forearm in a neutral position. The maximum value of a total of three tests was recorded. After 1 minute of rest, the left hand was tested [16]. Bioelectrical impedance analysis was performed with the InBodyS10 according to the manufacturer's (InBody; Biospace, Seoul, Korea) recommendations in the supine position to measure muscle mass. The muscle mass $(\mathrm{kg})$ in each limb divided by the square of the height $\left(\mathrm{m}^{2}\right)$ was defined as the skeletal muscle mass index (SMI). A low muscle mass was defined as less than 2 standard deviation (SD) of the mean of the sex-specific young reference group [17].

One physician assessed the symptoms and health status of patients before and after exercise. The COPD Assessment Test and the St. George's Respiratory Questionnaire were used to evaluate the symptoms and quality of life of our patients. The COPD Assessment Test is a short and simple questionnaire that estimates the degree to which the disease affects patients' lives. The score ranges from 0 to 40 : the higher the score, the more severe the symptoms [18]. The St. George's Respiratory Questionnaire assesses how symptoms affect overall health, daily life, and the perceived wellbeing of people with respiratory disease [19]. It consists of 50 items and is divided into three areas: symptoms, activity, and impact. This questionnaire results in a score from 0 to 100 , where 0 indicates the best health-related quality of life. 
Higher scores indicate a lower quality of life. The body mass index, degree of airflow obstruction, dyspnea, and exercise capacity (BODE index), which estimates the mortality in COPD patients, was determined through a chart review of subjects [20].

\section{Statistical Analysis}

Data in the text and tables are presented as mean $\pm \mathrm{SD}$. In addition, 95\% confidence interval are presented for each major outcome. A $p$-value below 0.05 was considered statistically significant. Normality tests were performed to compare continuous variables before and after PR. A paired-t test was used for variables shown to be normally distributed in the Kolmogorov-Smirnov and Shapiro-Wilk test. The Wilcoxon signed-rank test was performed on categorical variables and some variables that were not normally distributed. All statistical analyses were performed using IBM SPSS Statistics for Windows, Version 22.0 (IBM Co., Armonk, NY, USA).

\section{Results}

Thirty subjects were enrolled in the study after screening. The study was completed by 14 subjects. The total dropout rate was $53.3 \%$. The causes of dropout differed. They included new limiting conditions such as musculoskeletal pain during PR (31\%), lack of awareness of benefit of PR (19\%), and acute exacerbation of COPD (19\%), transport problems (19\%). When analyzed on 14 subjects who completed the training, the mean age was $67.64 \pm 7.77$ years, and males accounted for $85.7 \%$ of subjects. According to the FEV1, the Global Initiative for Chronic Obstructive Lung Disease [4] COPD stage 2 accounted for the largest proportion with $35.7 \%(n=5)$ of patients. The mean 6MWD was $474.93 \pm$ $120.48 \mathrm{~m}$, and the mean modified medical research council scale score was $1.43 \pm 0.85$ (Table 2). Adherence was defined as the number of attending a PR session and conducting a program completely. The mean adherence rate to the PR program was $89.3 \%$ among patients who completed the training.

The baseline and post PR results of 14 subjects were analyzed. A significant improvement of $43.57 \pm 39.43 \mathrm{~m}$ was observed in the 6MWT, but no significant difference was noted in the other functional tests (Table 3 ). A comparison of the before and after results for the subjective symptom questionnaires is shown in Table 4. In the St. George's Respiratory Questionnaire, no significant differences were found regarding symptoms and impact, but significant improvement
Table 2. Baseline subjects characteristics $(\mathrm{N}=14)$

\begin{tabular}{lc}
\hline \multicolumn{1}{c}{ Variable } & Value \\
\hline Age $(\mathrm{y})$ & $67.64(7.77)$ \\
Sex & \\
$\quad$ Male & $12(85.7)$ \\
$\quad$ Female & $2(14.3)$ \\
BMI $\left(\mathrm{kg} / \mathrm{m}^{2}\right)$ & $21.46(2.84)$ \\
mMRC (grade) & $1.43(0.85)$ \\
FEV $(\%$ predicted) & $55.50(21.60)$ \\
GOLD COPD stage (n) & \\
I & $3(21.4)$ \\
II & $5(35.7)$ \\
III & $4(28.6)$ \\
IV & $2(14.3)$ \\
6MWD (m) & $474.93(120.48)$ \\
Grip strength (kg) & \\
Male, percentage below cut off value & $34.62(7.45), 16.7$ \\
Female, percentage below cut off value & $21.45(2.62), 0$ \\
SMI (kg/m $\left.{ }^{2}\right)$ & \\
Male, percentage below cut off value & \\
Female, percentage below cut off value & $6.69(1.17), 50$ \\
\hline
\end{tabular}

Values are presented as $\mathrm{n}(\%)$ or mean $(\mathrm{SD})$. BMI: body mass index, mMRC: the modified medical research council dyspnea scale, $\mathrm{FEV}_{1}$ : forced expiratory volume in one second, GOLD: The Global Initiative for Chronic Obstructive Lung Disease, COPD: chronic obstructive pulmonary disease, 6MWD: 6 minute walk distance, SMI: skeletal muscle mass index.

${ }^{\mathrm{a}}$ The cut off values according to Asian Working Group for Sarcopenia 2014.

was seen in the activity and total score.

\section{Discussion}

Our study investigated the effect of an 8-week hospitalbased PR program with twice-weekly sessions in patients with COPD who complained of respiratory symptoms affecting their daily life. In previous studies, the minimal clinically important difference (MCID) in the 6MWD after COPD PR was suggested to be 37-71 $\mathrm{m}$ [21,22]. In our study, the difference in 6MWD after the PR program was $43.57 \mathrm{~m}$, so it can be considered that it is compatible with MCID of 6MWD. A meta-analysis found that the longer the duration of treatment (at least 6 months) and the more exercise sessions (more than 28) patients participate in, the greater the difference in the 6MWD [23].

Sarcopenia is reported in approximately $15 \%-25 \%$ of patients with stable COPD [24,25]. According to the criteria of the Asian Working Group for Sarcopenia, 16.7\% of the males and $33.3 \%$ of the females in our study had a grip strength below the cut-off value and therefore were consid- 
Table 3. Mean differences from baseline to end of PR in $6 \mathrm{MWD}$, pulmonary function, respiratory and grip strengths, skeletal muscle mass in training group

\begin{tabular}{lcccc}
\hline \multicolumn{1}{c}{ Outcomes } & Baseline & After 16 sessions & difference $(95 \% \mathrm{CI})$ & $p$-value \\
\hline 6MWD $(\mathrm{m})$ & $474.93(120.48)$ & $518.50(134.79)$ & $43.57(20.80-66.34)$ & $0.001 *$ \\
$\mathrm{PCF}(\mathrm{L} / \mathrm{min})$ & $270.36(117.46)$ & $284.29(106.90)$ & $13.93(47.40)(-13.44-41.30)$ & 0.292 \\
$\mathrm{MIP}\left(\mathrm{cmH}_{2} \mathrm{O}\right)$ & $73.71(35.71)$ & $75.07(32.06)$ & $1.36(13.52)(-6.45-9.16)$ & 0.713 \\
$\mathrm{MEP}\left(\mathrm{cmH}_{2} \mathrm{O}\right)$ & $94.57(43.09)$ & $94.93(42.44)$ & $0.36(26.16)(-14.75-15.46)$ & 0.960 \\
Left grip strength $(\mathrm{kg})$ & $30.44(7.60)$ & $31.82(9.08)$ & $1.38(4.10)(-0.99-3.75)$ & 0.231 \\
Right grip strength $(\mathrm{kg})$ & $32.69(8.45)$ & $34.82(9.96)$ & $2.13(3.96)(-0.16-4.42)$ & 0.051 \\
FEV $(\%$ predicted) & $56.70(20.77)$ & $55.83(23.05)$ & $-0.88(18.50)(-11.56-9.81)$ & 0.279 \\
SMI $\left(\mathrm{kg} / \mathrm{m}^{2}\right)$ & $6.61(1.15)$ & $6.21(2.08)$ & $-0.40(2.09)(-1.60-0.81)$ & 0.451 \\
BODE index & $3.29(2.20)$ & $3.21(2.01)$ & $-0.07(0.62)(-0.43-0.28)$ & 0.655 \\
\hline
\end{tabular}

Values are presented as mean (SD).

PR: pulmonary rehabilitation, 6MWD: 6 minute walk distance, CI: confidence interval, PCF: peak cough flow, MIP: maximal inspiratory pressure, MEP: maximal expiratory pressure, $\mathrm{FEV}_{1}$ : forced expiratory volume in one second, SMI: skeletal muscle mass index, BODE index: body mass index, degree of obstruction, dyspnea, and exercise capacity.

* Statistically significant at $p<0.05$.

Table 4. Differences from baseline to end of PR in SGRQ and CAT in the training group

$(\mathrm{N}=14)$

\begin{tabular}{lcccc}
\hline Types of Questionnaire & Baseline & After 16 sessions & Mean difference (95\% CI) & $p$-value \\
\hline SGRQ (score) & & & & \\
Symptoms & $39.19(16.41)$ & $32.48(16.54)$ & $6.70(-2.78-16.19)$ & 0.151 \\
Activity & $48.00(21.83)$ & $37.54(23.93)$ & $10.46(0.18-20.75)$ & $0.047^{*}$ \\
Impacts & $12.09(12.28)$ & $8.59(9.15)$ & $3.50(-2.84-9.84)$ & 0.326 \\
Total & $27.48(14.30)$ & $21.34(12.95)$ & $6.14(-0.78-13.06)$ & $0.022^{*}$ \\
CAT & $10.43(7.19)$ & $9.07(6.02)$ & $1.36(-1.03-3.73)$ & 0.172 \\
\hline
\end{tabular}

Values are presented as mean (SD).

PR: pulmonary rehabilitation, SGRQ: St. George's Respiratory Questionnaire score, CAT: COPD assessment test, COPD: chronic obstructive pulmonary disease.

*Statistically significant at $p<0.05$.

ered to have sarcopenia prior to the intervention [26]. Based on their muscle mass, $37.5 \%$ of the males and $83.3 \%$ of the females were below the cut-off defined for Asian patients. According to the revised criteria of European Working Group on Sarcopenia in Older People, seven patients (23.3\%) would have been diagnosed with sarcopenia because they did not meet the criteria for muscle strength and mass [27]. The PR program did not lead to a significant improvement in the index of SMI or the MIP and MEP as indicators of respiratory strength. It seems that insufficient frequency and time of strengthening exercise did not make a significant difference in muscle mass or strength. We also did not find significant changes in the findings of pulmonary function tests before and after the PR program, similar to another study [28].

An analysis of six clinical studies reporting St. George's Respiratory Questionnaire scores after PR revealed a clinically significant reduction of 4 points or more [29,30]. PR has been shown to improve all areas of the St. George's
Respiratory Questionnaire significantly except for the symptoms [31]. In this study, a significant decrease of 10.46 points in the activity area and 6.14 points in total score were achieved. This means that short-term PR can achieve a significant improvement in the quality of life of patients.

The BODE index includes the body mass index (BMI; B), degree of obstruction (O), dyspnea (D), and exercise capacity $(\mathrm{E})$, which are all independent predictors of survival in COPD [20]. In a previous study, the BODE index was improved by -0.9 after 3 months of rehabilitation with 24 two-hour sessions [32]. The only BODE index area that can be changed with short-term rehabilitation is exercise capacity. However, the BODE index defines $>350 \mathrm{~m}$ in the $6 \mathrm{MWD}$ as the best result, so there is no room for improvement in patients with an initial $6 \mathrm{MWD}>350 \mathrm{~m}$. In this study, the mean initial 6MWD was $474.93 \mathrm{~m}$, which excluded a relevant change in the BODE index in the first place.

According to the Global Initiative for Chronic Obstructive 
Lung Disease [4], PR as a non-pharmacological treatment of COPD shows a high level of evidence for its effectiveness, particularly regarding dyspnea-related quality of life and exercise capacity. We found similar results in our study, and this may be significant for South Korean patients because comprehensive PR has been covered since December 2016 by the Korean National Health Insurance.

Many authors report barriers and poor attendance to rehabilitation [33]. It is often difficult to recommend the registration of PR. Also, many referral patients do not visit outpatient clinics. Of the 556 patients diagnosed with COPD in our hospital, only 59 patients visited the outpatient PR clinic. The dropout rate among our patients was $53.3 \%$. In the UK, where PR is long established, attendance is reported to be less than $50 \%$, which is similar to our findings [34]. Studies in countries where PR is an accepted treatment have reported a $23 \%$ to $31 \%$ failure rate to complete a PR program of 2 months among COPD patients, confirming the difficulty of initiating and continuing PR $[35,36]$. The reasons why patients did not continue PR varied and included acute exacerbation of their COPD, the occurrence of new limiting conditions, their COPD being too debilitating to exercise, and transport problems [37]. We found similar reasons when we analyzed our dropouts, and the most common was debilitating issues such as knee pain. In addition, when comparing the dropouts with the patients who completed the program, a significant difference in the time spent on transportation was found, suggesting that problems with transportation present a major barrier to PR.

There are some limitations to this study. First, comprehensive PR has just recently started to be implemented in Korea, and it was difficult to ask patients and medical staff to participate in the study because they do not yet fully understand the effects and implications of PR. This prevented us from recruiting a control group, and we could only compare patient characteristics before and after the intervention. Furthermore, the high dropout rate affected our sample size and therewith the statistical power of our study.

This study showed that an 8-week hospital-based PR program improved exercise capacity and quality of life in a small group of COPD patients. It is important to note that comprehensive PR has only recently been established in South Korea. In view of the low attendance and high dropout rates, we conclude that it is necessary to improve patient motivation and education. We identified COPD exacerbations, transportation problems, and comorbidity as barriers to PR in the elderly. Future research will need to consider this clin- ical experience in South Korea and find ways to improve attendance of PR.

\section{Acknowledgements}

The authors would like to thank Pusan National University Hospital Regional Center for Respiratory Diseases for its support of this work.

This work was supported by clinical research grant from Pusan National University Hospital in 2020.

\section{Conflict of Interest}

The authors declared no potential conflicts of interest with respect to the authorship and/or publication of this article.

\section{References}

1. Spruit MA, Singh SJ, Garvey C, ZuWallack R, Nici L, Rochester $\mathrm{C}$, et al. An official American Thoracic Society/European Respiratory Society statement: key concepts and advances in pulmonary rehabilitation. Am J Respir Crit Care Med 2013;188:e1364.

2. Hill K, Vogiatzis I, Burtin C. The importance of components of pulmonary rehabilitation, other than exercise training, in COPD. Eur Respir Rev 2013;22:405-13.

3. Yoo KH, Kim YS, Sheen SS, Park JH, Hwang YI, Kim SH, et al. Prevalence of chronic obstructive pulmonary disease in Korea: the fourth Korean National Health and Nutrition Examination Survey, 2008. Respirology 2011;16:659-65.

4. Vogelmeier CF, Criner GJ, Martinez FJ, Anzueto A, Barnes PJ, Bourbeau J, et al. Global strategy for the diagnosis, management, and prevention of chronic obstructive lung disease 2017 report. GOLD executive summary. Am J Respir Crit Care Med 2017; 195:557-82.

5. Ries AL, Bauldoff GS, Carlin BW, Casaburi R, Emery CF, Mahler DA, et al. Pulmonary rehabilitation: joint ACCP/AACVPR evidence-based clinical practice guidelines. Chest 2007;131(5 Suppl):4S-42S.

6. The Korean Academy of Tuberculosis and Respiratory Diseases. Consensus document on pulmonary rehabilitation in Korea 2015. Seoul: The Korean Academy of Tuberculosis and Respiratory Diseases; 2015.

7. Riario-Sforza GG, Incorvaia C, Paterniti F, Pessina L, Caligiuri $\mathrm{R}$, Pravettoni C, et al. Effects of pulmonary rehabilitation on exercise capacity in patients with COPD: a number needed to treat study. Int J Chron Obstruct Pulmon Dis 2009;4:315-9.

8. Kisner C, Colby LA, Borstad J. Therapeutic exercise: foundations and techniques. 7th ed. Philadelphia (PA): F.A. Davis; 2018.

9. Casciari RJ, Fairshter RD, Harrison A, Morrison JT, Blackburn $\mathrm{C}$, Wilson AF. Effects of breathing retraining in patients with chronic obstructive pulmonary disease. Chest 1981;79:393-8.

10. Nici L, Donner C, Wouters E, Zuwallack R, Ambrosino N, 
Bourbeau J, et al; ATS/ERS Pulmonary Rehabilitation Writing Committee. American Thoracic Society/European Respiratory Society statement on pulmonary rehabilitation. Am J Respir Crit Care Med 2006;173:1390-413.

11. Dohoney P, Chromiak JA, Lemire D, Abadie BR, Kovacs C. Prediction of one repetition maximum (1-RM) strength from a 4-6 RM and a 7-10 RM submaximal strength test in healthy young adult males. J Exerc Physiol 2002;5:54-9.

12. Gea J, Pascual S, Casadevall C, Orozco-Levi M, Barreiro E. Muscle dysfunction in chronic obstructive pulmonary disease: update on causes and biological findings. J Thorac Dis 2015;7: E418-38.

13. American College of Sports Medicine. ACSM's guidelines for exercise testing and prescription. 9th ed. Philadelphia (PA): Lippincott Williams \& Wilkins; 2013.

14. ATS Committee on Proficiency Standards for Clinical Pulmonary Function Laboratories. ATS statement: guidelines for the six-minute walk test. Am J Respir Crit Care Med 2002;166:1117.

15. Becklake M, Crapo R, Buist S. American Thoracic Society Statement. Lung function testing: selection of reference values and interpretive strategies. Am Rev Respir Dis 1991;144:1202-18.

16. Lagerström C, Nordgren B. On the reliability and usefulness of methods for grip strength measurement. Scand J Rehabil Med 1998;30:113-9.

17. Kim SH, Shin MJ, Shin YB, Kim KU. Sarcopenia associated with chronic obstructive pulmonary disease. J Bone Metab 2019; 26:65-74.

18. Jones PW, Harding G, Berry P, Wiklund I, Chen WH, Leidy NK. Development and first validation of the COPD Assessment Test. Eur Respir J 2009;34:648-54.

19. Jones PW, Quirk FH, Baveystock CM, Littlejohns P. A self-complete measure of health status for chronic airflow limitation. The St. George's Respiratory Questionnaire. Am Rev Respir Dis 1992;145:1321-7.

20. Celli BR, Cote CG, Marin JM, Casanova C, Montes de Oca M, Mendez RA, et al. The body-mass index, airflow obstruction, dyspnea, and exercise capacity index in chronic obstructive pulmonary disease. N Engl J Med 2004;350:1005-12.

21. Make B. How can we assess outcomes of clinical trials: the MCID approach. COPD 2007;4:191-4.

22. Redelmeier DA, Bayoumi AM, Goldstein RS, Guyatt GH. Interpreting small differences in functional status: the Six Minute Walk test in chronic lung disease patients. Am J Respir Crit Care Med 1997; 155:1278-82

23. Lacasse Y, Goldstein R, Lasserson TJ, Martin S. Pulmonary rehabilitation for chronic obstructive pulmonary disease. Cochrane Database Syst Rev 2006;(4):CD003793.
24. Byun MK, Cho EN, Chang J, Ahn CM, Kim HJ. Sarcopenia correlates with systemic inflammation in COPD. Int $\mathrm{J}$ Chron Obstruct Pulmon Dis 2017;12:669-75.

25. Jones SE, Maddocks M, Kon SS, Canavan JL, Nolan CM, Clark AL, et al. Sarcopenia in COPD: prevalence, clinical correlates and response to pulmonary rehabilitation. Thorax 2015;70:2138.

26. Chen LK, Liu LK, Woo J, Assantachai P, Auyeung TW, Bahyah $\mathrm{KS}$, et al. Sarcopenia in Asia: consensus report of the Asian Working Group for Sarcopenia. J Am Med Dir Assoc 2014;15: 95-101.

27. Cruz-Jentoft AJ, Bahat G, Bauer J, Boirie Y, Bruyère O, Cederholm T, et al. Sarcopenia: revised European consensus on definition and diagnosis. Age Ageing 2019;48:16-31.

28. Nici L, Lareau S, ZuWallack R. Pulmonary rehabilitation in the treatment of chronic obstructive pulmonary disease. Am Fam Physician 2010;82:655-60.

29. Jones PW. St. George's respiratory questionnaire: MCID. COPD 2005;2:75-9.

30. Lacasse Y, Martin S, Lasserson TJ, Goldstein RS. Meta-analysis of respiratory rehabilitation in chronic obstructive pulmonary disease. A Cochrane systematic review. Eura Medicophys 2007; 43:475-85.

31. Puhan MA, Gimeno-Santos E, Cates CJ, Troosters T. Pulmonary rehabilitation following exacerbations of chronic obstructive pulmonary disease. Cochrane Database Syst Rev 2016;12: CD005305.

32. Cote CG, Celli BR. Pulmonary rehabilitation and the BODE index in COPD. Eur Respir J 2005;26:630-6.

33. Johnston KN, Young M, Grimmer KA, Antic R, Frith PA. Barriers to, and facilitators for, referral to pulmonary rehabilitation in COPD patients from the perspective of Australian general practitioners: a qualitative study. Prim Care Respir J 2013;22:319-24.

34. Keating A, Lee A, Holland AE. What prevents people with chronic obstructive pulmonary disease from attending pulmonary rehabilitation? A systematic review. Chron Respir Dis 2011; 8:89-99.

35. Fischer MJ, Scharloo M, Abbink JJ, van't Hul AJ, van Ranst D, Rudolphus A, et al. Drop-out and attendance in pulmonary rehabilitation: the role of clinical and psychosocial variables. Respir Med 2009;103:1564-71.

36. Garrod R, Marshall J, Barley E, Jones PW. Predictors of success and failure in pulmonary rehabilitation. Eur Respir J 2006;27: 788-94.

37. Hayton C, Clark A, Olive S, Browne P, Galey P, Knights E, et al. Barriers to pulmonary rehabilitation: characteristics that predict patient attendance and adherence. Respir Med 2013;107:401-7. 